\title{
Non-specificity of Laboratory Test for Diagnosis of Multiple Sclerosis
}

\author{
J. MERTIN, D. HUGHES, E. A. CASPARY, A. M. THOMSON, J. B. FOSTER, \\ E. G. STEWART-WYNNE
}

British Medical fournal, 1974, 4, 567-569

\section{Summary}

It has been claimed that the inhibiting effect of linoleic acid on the macrophage electrophoretic mobility test provides a specific laboratory method for the diagnosis of multiple sclerosis (M.S.) and may also enable susceptible relatives of M.S. patients to be identified. Three trials of the method under double-blind conditions have failed to confirm that the test is diagnostically useful.

\section{Introduction}

An inhibitory effect of polyunsaturated fatty acids on the response of human lymphocytes to antigens was shown by the macrophage electrophoretic mobility test (Mertin et al., 1973) and confirmed by lymphocyte transformation (Mertin and Hughes, 1974; Mertin et al., 1974). Subsequently Field et al. (1974) claimed that the degree of inhibition was so much greater with lymphocytes from patients with multiple sclerosis (M.S.) than from those with other neurological diseases (O.N.D.) ( $91 \%$ compared with $47 \%$ ) that this could be used to provide a specific laboratory test for the diagnosis of M.S. They also claimed that the test enabled them to identify apparently normal relatives of patients with M.S. who might develop the disease later. Field (1973) had previously suggested that "the establishment of a child-testing service would be a rational and inexpensive first step in the study of the prevention of the disease."

These claims were based on the results of exploratory studies in the M.R.C. Demyelinating Diseases Unit, mostly during the summer of 1973 . We believed that the investigations should be repeated with the discipline of a formal experimental design under strictly double-blind conditions. Trials on this basis were initiated in October and concluded in December 1973.

\section{Subjects and Methods}

M.S. patients were selected according to the criteria of Allison and Miller (see McAlpine et al., 1972). All had a history of relapses and remissions, clinical evidence of involvement of two or more parts of the central nervous system not due to a single focal lesion, and where appropriate had been investigated to exclude other disorders. Patients with O.N.D. were undergoing routine inpatient investigation, care being taken to exclude cases in which a possibility of M.S. existed. No patient in either group was receiving any form of immunosuppressive treatment.

\footnotetext{
M.R.C. Demelinating Diseases Unit, Newcastle General Hospital, Newcastle upon Tyne NE4 6BE

J. MERTIN, M.D., Visiting Research Fellow

D. HUGHES, B.SC., Technical Officer
E. A. CASPARY, M.SC., M.R.C.PATH., Immunologist

A. M. THOMSON, B.SC., F.R.C.o.G., Acting Director

Regional Neurological Centre, Newcastle General Hospital, Newcastle upon Tyne NE4 $6 \mathrm{BE}$

J. B. FOSTER, M.D., F.R.C.P., Neurologist

E. G. STEWART-WYNNE, M.B., M.R.C.P., Registrar
}

Blood specimens were defibrinated and sent to the laboratory bearing code numbers only, the code itself being concealed. Laboratory staff did not know the clinical source of the specimens and clinical staff were not told the laboratory findings until each trial was complete.

Lymphocytes were separated and treated, macrophage electrophoretic mobility was measured, and the percentage inhibition by linoleic acid was calculated as described by Field et al. (1974). These procedures were undertaken by the same staff as had done the earlier work, in the same laboratories, and under conditions which were not considered to have changed in any material respect.

\section{Results and Discussion}

The first double-blind trial was expected to confirm the earlier findings; the main aim was to compare results from cases of M.S. with those from patients with a wider range of O.N.D. than had previously been examined. The trial was concluded and the codes were "broken" when specimens from 66 patients had been examined. They proved to have been derived from nine patients with M.S. and 57 with O.N.D.

Contrary to expectation none of the M.S. cases showed high levels of inhibition (about 90\%) whereas inhibitions in cases of O.N.D. were widely distributed, from $42 \%$ to $96 \%$ (table I). Since these results contradicted the earlier findings laboratory staff were asked to check all equipment and materials and a second double-blind trial was organized.

TABLE I-Distribution of Percentage Inhibitions in First Double-blind Trial (P.P.D. Antigen, 0.08 t F mg/ml Linoleic Acid)

\begin{tabular}{|c|c|c|c|c|c|}
\hline \multicolumn{4}{|c|}{$\%$ Inhibition } & M.S. Cases $(n=9)$ & O.N.D. Cases $(n=57)$ \\
\hline $\begin{array}{l}<50 \\
50-59 \\
60-69 \\
70-79 \\
80-89 \\
\geqslant 90\end{array}$ & $\begin{array}{l}\cdots \\
\because \\
\cdots \\
\cdots \\
\end{array}$ & $\begin{array}{l}. . \\
\because \\
\because \\
\therefore\end{array}$ & $\begin{array}{l}\ldots \\
\because \\
\because \\
\cdots\end{array}$ & $\begin{array}{l}7 \\
1 \\
1\end{array}$ & $\begin{array}{r}26 \\
4 \\
1 \\
6 \\
3 \\
17 \\
\end{array}$ \\
\hline Mean & S.D. & .. & . & $50.9 \pm 9 \cdot 1$ & $66 \cdot 8 \pm 20 \cdot 8$ \\
\hline
\end{tabular}

This second trial was designed to test the hypothesis that the test could distinguish cases of M.S. from cases of O.N.D. according to the criteria of Field et al. (1974), which had become available in draft form. Since the diagnostic specificity of these criteria appeared to be so high large numbers of cases were not necessary. Two samples of blood were taken at different times within 24 hours from six patients with M.S. and six with O.N.D. and delivered to the laboratory bearing random numbers only.

The results (table II) again failed to show any consistent difference between cases of M.S. and of O.N.D. Agreement between replicates was excellent in six pairs of measurements but those on samples from the remaining six patients differed from $11 \%$ to $46 \%$ between pairs.

A summary of the measurements made in these two doubleblind trials together with those from a third double-blind trial for which Professor Field supplied duplicate specimens from each of a series of patients and which also yielded negative and discordant results is given in fig. 1. The measurements are plotted against a background of the ranges reported by Field 
TABLE II-Percentage Inhibitions in Second Double-blind Trial: Two Separate Samples from Six Cases of M.S. and Six of O.N.D.

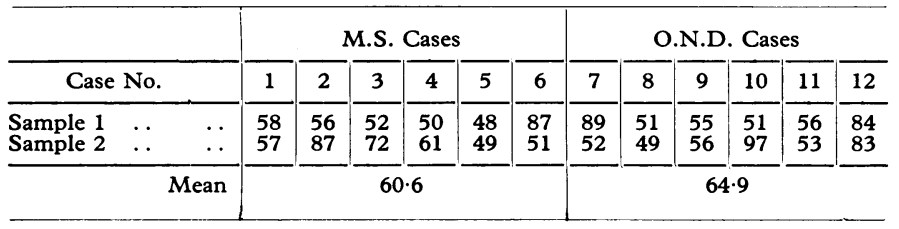

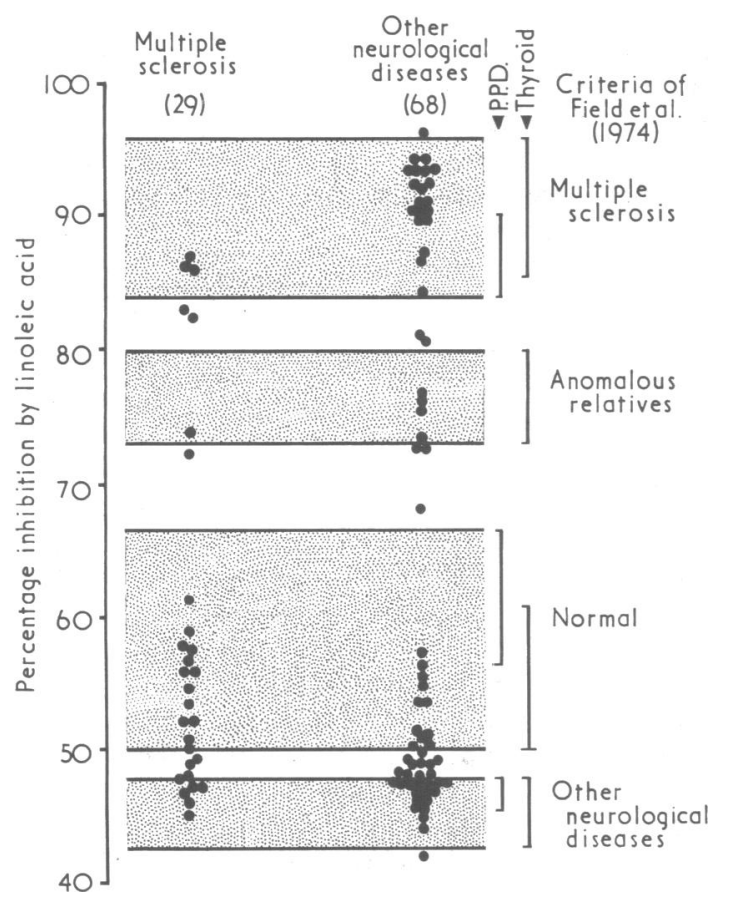

FIG. 1-Percentage inhibitions in specimens from patients with M.S. and with O.N.D. in three double-blind trials. Shaded bands indicate ranges of diagnostic categories reported by Field et al. (1974). P.P.D.= Purified protein derivative of tuberculin.

et al. (1974) for their cases of M.S. and O.N.D. as well as for their normal subjects and "anomalous" relatives of M.S. patients. The data from the double-blind trials completely failed to discriminate between M.S. and O.N.D.

A short letter cautioning against premature assumptions that a reliable laboratory diagnostic test for M.S. was available was therefore written by Foster et al. (1974) and appeared in the same issue of the British Medical fournal as the report by Field et al. (1974).

Shenton (1974) then asserted his faith in the earlier data and stated that the contradictory results of the double-blind trials were attributable to "differences in the totality of experimental conditions." In particular, he suggested that the guinea-pigs from which macrophages were harvested might have been exposed to droplet immunization with common viral antigens: "On the principle of Occam's razor one need go no further in seeking an explanation of the alleged discrepancy." The available evidence seems to rule out the hypothesis that the macrophages became unreliable. Field (1974) pointed out that "inadvertent guinea-pig exposure to infections may be monitored by measuring the response of peritoneal exudate cells to P.P.D. or E.F. . . . A rise above $1.5 \%$ in macrophage slowing should be regarded as unacceptable." Measurements of macrophage slowing from May to December 1973 are shown in fig. 2. There was no change during the autumn, and only one measurement was marginally above the specified upper limit

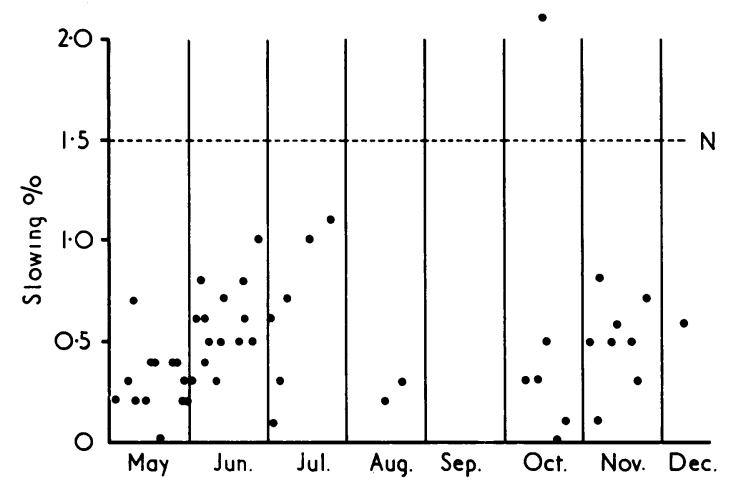

FIG. 2-Guinea-pig macrophage control values, May to December 1973 (see text). Line $\mathrm{N}$ indicates maximum acceptable value (Field, 1974).

of normal-as it happens, not on a day when any test for a double-blind trial was made. Again, measurements of macrophage migration times with lymphocytes alone and with lymphocytes plus antigen (P.P.D. or thyroid) remained extremely stable throughout the whole period of May to December 1973. For such reasons we do not consider to be valid suggestions that the experimental conditions might have changed.

In our view the results of the double-blind trials are technically no less reliable than those of the earlier experiments reported by Field et al. (1974). A possible explanation for the discrepant results could be that the earlier data were not obtained under strict double-blind conditions; the possibility of subjective bias, therefore, cannot be wholly excluded.

The cytopherometer is a fickle instrument and the choice of macrophages for measurement involves an apparently unavoidable subjective element (Shenton et al., 1973). The diagnostic criteria of Field et al. (1974) are based on the measurement, by stopwatch, of small differences of macrophage migration times-smaller than those involved in the immunodiagnosis of cancer by the macrophage electrophoretic mobility method (Caspary and Field, 1971; Pritchard et al., 1972). Irrespective of the technical hazards of the method the extremely small standard deviations and narrow ranges reported by Field et al. (1974) for each of their clinical categories implies an unexpectedly high level of biological homogeneity within categories. It therefore seems reasonable to express scepticism, especially since some duplicate measurements, made under blind conditions on specimens from the same patients, disagreed as widely as the overall range of the reported diagnostic scale.

Comparison of lymphocytes from patients with M.S. and with O.N.D. by the lymphocyte transformation technique has suggested that linoleic acid inhibition may indeed by somewhat greater in M.S. (Mertin et al., 1974). But this appears to be a minor difference between groups. Individual cases from the two groups overlap extensively, so that such measurements cannot be used for diagnostic purposes. Whether the macrophage electrophoretic mobility test is capable of showing similar group differences remains to be seen. At present, however, the diagnostic specificity claimed by Field et al. (1974) for linoleic acid inhibition with the macrophage electrophoretic mobility test must be regarded as unproved. For that reason it is not justifiable to make clinical recommendations on the basis of that test.

We thank Mr. W. Z. Billewicz for statistical advice, Mr. A. Keith for dealing with the guinea-pigs, Mrs. J. Cobill for technical help, and several other colleagues for advice and criticism. J. Mertin is supported by grants from the Deutsche Akademische Austauschdienst and from the Deutsche Forschungsgemeinschaft.

\section{References}

Caspary, E. A., and Field, E. J. (1971). British Medical fournal, 2, 613. 
Field, E. J. (1973). Lancet, 2, 1080

F 'd, E. J. (1974). British Medical fournal, 1, 245

Fic,d, E. J., Shenton, B. K., and Joyce, G. (1974). British Medical fournal, 1,412 .

Foster, J. B., Mertin, J., and Thomson, A. M. (1974). British Medical fournal, 1, 452

McAlpine, D., Lumsden, C. E., and Acheson, E. D. (1972). Multiple Sclerosis: A Reappraisal. Edinburgh and London, Churchill Livingstone.
Mertin, J., and Hughes, D. (1974). International Archives of Allergy and Applied Immunology. In press.

Mertin, J., Shenton, B. K., and Field, E. J. (1973). British Medical fournal, 2, 777 .

Mertin, J., Hughes, D., and Stewart-Wynne, E. (1974). Lancet, 1, 1005.

Pritchard, J. A. V., et al. (1972). Lancet, 2, 627.

Shenton, B. K. (1974). British Medical fournal, 1, 574

Shenton, B. K., Hughes, D., and Field, E. J. (1973). British fournal of Cancer, 28, Suppl. No. 1, p. 215.

\section{PRELIMINARY COMMUNICATION}

\section{Effective Treatment for Paraquat Poisoning in Rats and its Relevance to Treatment of Paraquat Poisoning in Man}

\author{
L. L. SMITH, A. WRIGHT, I. WYATT, \\ M. S. ROSE
}

British Medical fournal, 1974, 4, 569-571

\section{Summary}

After oral administration of a lethal dose of paraquat to rats the plasma concentration remained relatively constant over four to 30 hours and was related to the paraquat content of the small intestine over the first 16 hours. During the first 30 hours the concentration of paraquat in the lung rose progressively above that of the plasma to levels which are known to cause pulmonary damage. A treatment has been devised which prevents the absorption of paraquat into the plasma and prevents accumulation of paraquat in the lung. This treatment consists of a stomach wash followed by four administrations of bentonite plus purgatives at two- to three-hour intervals. Even when treatment was delayed until 10 hours after administration of paraquat $80 \%$ survival was obtained. The relevance of this treatment to paraquat poisoning in man is discussed in the light of the finding that slices of human lung accumulate paraquat in the same way as those of rat lung.

\section{Introduction}

Paraquat, a widely used herbicide, has caused death in man after ingestion. In most cases death has resulted from extensive pulmonary damage, characterized initially by oedema, haemorrhage, and at later stages fibrosis (Bullivant, 1966; Bronkhorst et al., 1968; Matthew et al., 1968). Except when extremely large amounts are taken signs of pulmonary damage are not usually seen for several days after ingestion and death may not occur for several weeks.

Paraquat has been shown to have a similar effect in experimental animals, the lungs being severely affected (Clark et al., 1966; Conning et al., 1969; Murray and Gibson, 1972). The

Central Toxicology Laboratory, Biochemical Mechanisms Unit, Imperial Chemical Industries Limited, Alderley Park, Cheshire SK10 4T]

L. L. SMITH, B.SC., Biochemist

A. WRIGHT, L.I.BIOL., Biochemist

I. WYATT, L.R.I.C., Biochemist

M. S. ROSE, B.SC., PH.D., Head of Biochemical Mechanisms Unit discovery of an energy-dependent accumulation of paraquat by rat lung in vitro (Rose et al., in press) shows the propensity of lung to take up paraquat over a long period of time from a low concentration in plasma, and, therefore, offers a possible explanation for the selectivity of paraquat for the lung and also, possibly, for the delay in onset of pulmonary changes.

Previous work in animals (Clark, 1971) has shown the efficacy of fuller's earth and bentonite in binding paraquat and preventing absorption from the gut. It was found, however, that a single dose of these materials was effective only when given within a few hours after paraquat administration. Our experiments were carried out to investigate in greater detail the relationships between gastrointestinal paraquat content and plasma and lung concentrations. The effect on survival of thorough purging of the gastrointestinal tract after a lethal dose of paraquat was also examined.

\section{Methods}

Measurement of Paraquat after Oral Administration.-Male, Alderley Park (Wistar-derived), specific pathogen-free rats (body weight 180-200 g) were starved for 24 hours before being dosed by gavage with $0.2 \mathrm{ml} / 100 \mathrm{~g}$ body weight of an aqueous solution of pure paraquat dichloride containing paraquat $340 \mu \mathrm{mol} / \mathrm{ml}$ and $50 \mu \mathrm{Ci} / \mathrm{ml}$ of methyl- ${ }^{14} \mathrm{C}$ paraquat (specific activity $30 \mathrm{mCi} / \mathrm{mmol}$, purchased from the Radiochemical Centre, Amersham). Animals were killed with halothane, blood taken by cardiac puncture, and the lungs, stomach, and small intestine removed. The contents of the stomach and small intestine were collected by thorough washing, and the amount of paraquat present in these contents and in plasma and lung was determined by measuring the radioactivity.

Treatment after Paraquat Administration.-After dosing with paraquat animals were left for four to 10 hours. The stomachs were then washed out with $5 \mathrm{ml}$ of $0.9 \%$ saline and each of the rats was given by mouth castor oil $0.5 \mathrm{ml}$, magnesium sulphate $250 \mathrm{mg} / \mathrm{kg}$ body weight in a small volume (about $0.4 \mathrm{ml}$ ), and a suspension of bentonite $7-10 \mathrm{ml}(7 \% \mathrm{w} / \mathrm{v})$. The castor oil and bentonite were administered a further three times at two- to three-hour intervals.

Measurement of Paraquat Accumulation in Slices of Human Lung.-Samples of fresh human lung were sliced and stored at room temperature in Krebs-Ringer phosphate buffer containing $200 \mathrm{mg} / 100 \mathrm{ml}(\mathrm{w} / \mathrm{v})$ glucose. Only slices with two cut surfaces were used. Slices (30-100 mg wet weight) were incubated in Krebs-Ringer phosphate (Umbreit et al., 1964) glucose $(3.0 \mathrm{ml})$ containing $0 \cdot 1 \mu \mathrm{Ci}$ methyl- ${ }^{14} \mathrm{C}$ paraquat (specific radioactivity $32 \mathrm{mCi} / \mathrm{mmol}$ ) and the required amount of paraquat dichloride to give final concentrations of $10^{-6}, 10^{-5}, 10^{-4}$, and $10^{-3} \mathrm{~mol} / \mathrm{l}$. Incubation was carried out in air in a shaking water bath at $37^{\circ} \mathrm{C}$. After incubation slices were blotted and dissolved in $1.0 \mathrm{ml}$ Soluene (Packard Instrument Co. Ltd) then $10 \mathrm{ml}$ of Dimilume scintillator (Packard Instrument Co. Ltd.) was added. Samples of incubation media $(0.1 \mathrm{ml})$ were diluted to $1.0 \mathrm{ml}$ with water, and $10 \mathrm{ml}$ of Instagel scintillator (Packard Instrument Co. Ltd.) was added. The radioactivity of all samples was measured using a liquid scintillation spectrometer. 